\title{
Strategic business-IT alignment of application software packages: Bridging the information technology gap
}

\author{
Wandi Kruger ${ }^{1}$ \\ Department of Accounting, Stellenbosch University, Private Bag X1, Matieland 7602, South \\ Africa
}

\begin{abstract}
An application software package implementation is a complex endeavour, and as such it requires the proper understanding, evaluation and redefining of the current business processes of an organisation to ensure that the implementation delivers on the objectives set at the start of the project.

Numerous factors exist that may contribute to the unsuccessful implementation of application software packages. However, the most significant contributor to the failure of an application software package implementation lies in the misalignment of the organisation's business processes with the end functionality of the application software package implemented. Misalignment is attributed to a gap that exists between the business processes of an organisation and the functionality the application software package has to offer to translate the business processes of an organisation into digital form when implementing and configuring an application software package. This gap is commonly referred to as the information technology (IT) gap.

Based on an extensive literature study, this article proposes to define and discuss the IT gap that specifically exists between the business processes of an organisation and application software packages acquired from a software supplier. Furthermore, this article makes recommendations for aligning the business processes of an organisation with the functionality of the application software package implemented. The end result of adopting these recommendations will be more successful application software package implementations for organisations.
\end{abstract}

\section{CATEGORIES AND SUBJECT DESCRIPTORS}

K6.1 [Management of computing and information systems]: Project and people management - strategic information systems planning

K6.3 [Management of computing and information systems]: Software management - software selection

K.m [Miscellaneous]

\section{KEYWORDS}

Strategic alignment; information technology gap; application software package

\section{INTRODUCTION}

By applying an application software package in an organisation, executives believe they will ultimately improve on earnings through improved operational efficiency, decrease in costs, enhanced ability to make knowledgeable decisions and creating competitive advantages by enabling innovative practices $[4,5,20,49]$. It is, however, expected that information technology (IT) implementation projects will become more turbulent and difficult in the future [35]. This situation will result in one of the most common challenges top management face: the decision to make significant investments in application software packages.
Although top management may perceive that acquiring an application software package may result in the enhancement of the organisation's performance, it is important to remember that implementing an application software package goes further than merely changing components; it usually requires a complete refit of the organisation itself [2]. This refit of the organisation entails the strategic alignment of business strategies and IT strategies [43]. For management wanting to refit the organisation and succeed in implementing application software packages within budget, within timeframe and with the appropriate functionality required, they would first

\footnotetext{
${ }^{1}$ E-mail: wandivanrenen@sun.ac.za
} 
need to evaluate their current business processes and, where necessary, reengineer or streamline their internal processes to suit operational requirements [48, 49]. However, based on a broad review of the literature, a significant number of application software package implementations are regarded as failures and do not always enhance improvements in the areas identified above.

Various studies have found that a large number of significant IT implementations result in waste and fail to provide a return to the entity, as the application software package implementations fail to achieve the original functional objectives set at the start of the IT project [21, 29]. For example in a study conducted by PriceWaterhouseCoopers in 2004, 10640 IT projects were surveyed and revealed that only 2.5 per cent of organisations achieve budget, scope and schedule targets in all IT projects [13]. This is in contrast to the 2004 study conducted by The Standish Group, which reported a higher success rate for IT projects at 29 per cent [18]. The Standish Chaos Report for 2006 showed that 35 per cent of IT projects were successful, which decreased by 3 per cent to a 32 per cent success rate, according to their 2009 study [18].

Why do application software package implementations still fail? Although this question has long drawn the attention of many academics and practitioners, it is still relevant today. In the opinion of Velcu [46], the most significant reason why IT implementations in general fail is that business strategies (business processes) are not aligned (or are misaligned) with the IT (application software package implemented) strategy. Misalignment, in the case of application software packages specifically, is attributed to a gap that exists between the business processes of an organisation and the functionality the application software package has to offer to translate the business processes of an organisation into digital form when implementing and configuring an application software package. This gap is commonly referred to as the IT gap.

\section{OBJECTIVE OF STUDY}

The purpose of this article is to define and explain the IT gap that exists between the business processes of an organisation and the end functionality of the application software package implemented, specifically acquired from an IT supplier. Based on an extensive literature study, this article further proposes recommendations that may be followed to ensure strategic alignment of business processes in an organisation with the end functionality of the application software package implemented.

This article aims to educate academics, organisational leaders, IT suppliers and IT and business decision-makers on the importance of properly identifying and defining business processes in an organisation and ensuring that proper alignment is achieved between the business processes and the application software package selected to implement in the organisation. This article will further increase the understanding of what the IT gap between business processes and application software packages specifically entails.

An organisation's success depends on how appropriately the application software package responsible for day-to-day activities operates. Organisations that can harness the ability to properly address the IT gap that exists between business processes and the application software package will be able to lower capital expenditure.

This article only focuses on application software packages acquired from a supplier. The technical issues regarding the implementation of application software packages are not addressed.

In the next section, the concept or theory of alignment is discussed, followed by a definition and discussion of characteristics of business processes and application software packages. The section concludes with a discussion of the influence of the IT supplier on the alignment of the business processes of the organisation and the functionality of the end product.

\section{CONCEPTUAL BACKGROUND}

\subsection{Strategic alignment}

Strategic business and IT alignment continues to lure attention, despite many years of research. This can be ascribed to the many practical challenges strategic business and IT alignment present [14]. Luftman [28] defines business-IT alignment in general as '[a]pplying Information Technology (IT) in an appropriate and timely way in harmony with business strategies, goals and needs'. Soh and Sia [38] define alignment with regard to application software packages as aligning the

'differences between structures embedded in the organisation (as reflected by its procedures, rules and norms) and those embedded in the package'.

Strategic business and IT alignment starts with the search for strategic information systems or an application software package for the organisation to assist in decisionmaking [16]. This search has been a key objective of the processes and methods used [20]. This resulted in a resource-based theory capability (or functionality) approach to information systems, which have become evident in recent years [16]. With this capability approach, the focus has moved to the implementation of an application software package with an overall functionality that is effective throughout the organisation, and not just in the IT department [32].

Henderson and Venkatraman developed a new model, namely the Strategic Alignment Model for IT alignment, elucidating the effect of IT functionality on all four areas of business strategy, IT strategy, organisational infrastructure and processes, and IT infrastructure and processes [20]. Their concept of strategic alignment is based on two domains: external and internal [20]. The external domain refers to the business arena, while the internal domain refers to how the information system infrastructure should be configured (in other words, the functionality thereof) [20].

Organisations may have different perspectives of IT alignment. Henderson and Venkatraman list four dominant alignment perspectives [20]. The strategy execution perspective entails that a business strategy has been articulated and is the driver for both organisational and information systems infrastructure design choices, whereas the technology transformation perspective involves the implementation of the chosen business strategy through the 
appropriate IT strategy and the articulation of the required information system infrastructure and processes [20]. The competitive potential alignment perspective 'seeks to identify the best set of strategic options for business strategy and the corresponding set of decisions pertaining the organizational infrastructure and processes' [20]. Lastly, the focus of the service level perspective is to build a world-class information system organisation.

The argument of this article is built upon the Strategic Alignment Model suggested by Henderson and Venkatraman, the two domains identified by them and the technology transformation perspective of IT alignment. The Strategic Alignment Model can be made applicable to organisations who are searching for a 'tool' to assist in aligning specific business processes with the end functionality of the application software package, provided that the organisation is willing to adopt a technology transformation perspective towards alignment.

Furthermore, alignment may take on different forms and the form depends on the need of the organisation. There may be a need to align external (IT infrastructure) IT domains and internal (IT strategy) domains of IT [20], or there may be a need to integrate business and IT domains (in other words, integrate business and IT strategy) [20]. The second need can be further subdivided into either strategic integration (the capability of IT functionality to shape and support business strategy) or operational integration (the link between organisational infrastructure and processes and information systems infrastructure and processes). This article explores the first need: strategic integration specifically with regard to the alignment of business processes with the end functionality of the application software package.

What makes business-IT alignment difficult to achieve is the dynamic, turbulent and continually changing nature of business and IT environments [21]. Chan et al. [9] stress that organisations should not focus on business strategic orientation or IT strategic orientation alone, but on both.

Because alignment remains an ill-defined concept that is difficult to understand and the IT literature is not consistent in describing what the IT strategies should be linked (or aligned) to, the author of this article consequently conducted a literature study in an effort to understand the meaning and dimensions of the strategic alignment of specific business processes with the end functionality of the application software package.

\subsection{Enablers of strategic alignment}

It is important to note that achieving strategic alignment between business processes and the end functionality of the application software package entails a number of influencing factors or enablers. Consideration should be given to all influencing factors and not one factor alone.

Various authors list different enablers of strategic alignment. For example, Luftman [28] lists the following factors as enablers of strategic alignment: senior executive support for IT; IT involved in strategy development; IT understands the business; business-IT partnership; wellprioritised IT projects; and IT demonstrates leadership. Reich and Benbasat [34] are of the opinion that integration between business planning and IT planning, shared domain knowledge, communications and past IT implementation success is essential in ensuring strategic alignment. The view expressed by Umble et al. [45], Taylor [42] and Zand and Sorensen [50] is that a major contributor to or enabler of implementation success is the proper definition of business objectives at the start of the implementation of the application software package. Brynjolfsson and Mendelson (as cited in Ehie \& Madsen) [17] support this view by stating that application software package implementation success is due to the ability of the application software package to match the organisation's requirements to solve business problems.

A study conducted by Kruger in 2011 on IT project failure and strategic alignment of business processes with the end functionality of application software packages concluded that there is not one single factor that will result in successful alignment, but a combination of factors [27]. The fact that more than one factor will result in successful alignment in general is further stressed by Chao and Chandra [10]. Thus, the integration of the factors listed above will assist organisations in properly aligning business processes and the end functionality of the application software package.

\subsection{Defining and discussing characteristics of application software packages and business processes}

Application software packages, for the purpose of this article, can be defined as computer software designed to help the operator to perform singular or multiple related, specific tasks. Examples of application software packages include accounting software, office suites and enterprise software [8].

A business process, for the purpose of this article, may be defined as a 'collection of related, structured activities or tasks that produce a specific service or product for a particular client or clients'. It often can be visualised with a flowchart as a sequence of activities [24].

Many characteristics of both application software packages and business processes may contribute towards misalignment of business processes with application software packages. The following characteristics of application software packages may contribute towards misalignment $[11,27]$ :

- Limited customisation functionality - this type of application software is developed for the mass market and not for a specific organisation, resulting in organisations changing business processes to suit the software instead of the other way round (a more detailed discussion follows in Section 5).

- Monolithic architecture - data input and output, data processing and user interface are not separate items but interwoven, which may work poorly in organisations with multiple users.

- Basic pre-defined workflow - this does not allow the user to introduce new components into the operation, which might be necessary to ensure proper alignment.

- Basic report-writing abilities - application software 
packages can only provide standard reports and no other type of reports that management of the organisation may require to assist them in their decision-making processes.

Inability of management to properly understand, identify and define business processes that are crucial for their business to be successful is a characteristic of misalignment of business processes [11]. A business process usually starts with a specific objective that the organisation has in mind and ends with the organisation reaching the objective [24]. If the organisation has no objective, alignment already fails at this stage, as there is no goal towards which to work. If the following characteristics of a business process are not in place or properly defined, it is most certain that proper alignment will not be achieved, as the application software package will then be tailored to an 'incorrect' objective [24]: definability (management should clearly define boundaries and the inputs and outputs of the business process); order (the process should consist of activities that are ordered in terms of their position in time and space); customer (a recipient of the outcome of the process); value-adding (the changes to the process must add value to the organisation); embeddedness (the process must be embedded in an organisational structure, as it cannot exist in itself); and cross-functionality (a process usually spans over several functions, although this is not always a necessity). A further detailed discussion of the characteristics falling within the scope of this article and other characteristics that might lead to or impact the misalignment of business processes follows in Section 5 .

Furthermore, it is necessary to understand the duality of interaction between the characteristics or design of an organisation and IT implementation to ensure proper alignment [14]. The discussions below is limited to smaller organisations, as the focus of this study was the alignment of application software packages supplied by vendors that smaller businesses usually would acquire.

The integration of technology and the organisation has become more obvious due to computers moving from their traditional role in the 'back office' to supporting the day-today activities of the organisation [6]. This led to organisations shifting their attention to business process redesign, which emphasised the interaction between the organisational design and investments in information systems [19]. Many characteristics exist that may influence alignment in an organisation. Below, two characteristics are briefly discussed, namely decision-making and the size of the organisation.

Brynjolfsson and Mendelson [7] are of the opinion that neither information systems nor the decision-making structure of organisations can be seen in isolation. It should be jointly determined [7] to ensure that the appropriate application software package is selected to support decision-making (by providing the appropriate information to support decision-making) in the organisation and achieve successful alignment thereof. An organisation can adopt either a centralised (it relies on one individual to make decisions and provide direction) or a decentralised (several individuals are responsible for making decisions) decisionmaking structure [7]. For example, in the case of a decentralised decision-making structure, the organisation may require collaborative computing abilities from IT (or the application software package). It is also important to note that where decision-making lies may depend on where the knowledge in the organisation is located [7]. Furthermore, the size of the organisation will also have an effect on IT implementation. Heikkila, Saarinen and Saaksjarvi (as cited in Doukidis, Lybereas \& Galliers) [14] list three organisational characteristics for small and large organisations that may influence IT implementation. The characteristics for small organisations are that computers are used more as tools and less as communication media; fewer stakeholders are involved in decision-making; and fewer resources are available to implement IT solutions. The three characteristics are shortly discussed below.

The first characteristic, the use of computers or IT need (or functionality of the application) of the organisation plays a major part in IT implementation. In other words, what exactly does the organisation need from IT to support the organisation reaching its business objectives? For example, a smaller company would not be able to invest a large amount of money into information systems and would typically acquire an application software package with a low cost of ownership and which is scalable. The type of industry the organisation is trading in will determine the needs of the organisation. For example, the fast-food industry would acquire an application software package that is easy to use by its employees with simple workflow and user interfaces (such as touch screens). With regards to the second characteristic, input from all stakeholders and not only those involved in decision-making is required to ensure that the correct application software package is selected for the organisation to ensure adequate alignment, as the decision-makers are not the only persons using the application software package. Thirdly, with fewer resources available, smaller businesses would rely more on shortterm subcontracting and/or suppliers of the application software package to achieve alignment of the application software package [14]. The influence of the supplier of the application software package is discussed in Section 3.4.

\subsection{The role of the application software package supplier in strategic alignment}

Velcu [46], IT Cortex [23] and Poli and Shenhar [33] share the opinion that strategic alignment of business strategies with the application software package functionalities is essential to ensure successful implementation.

One of the reasons for application software package implementation failures may be that the end-user organisations do not always have the in-house expertise to handle technical issues relating to implementation of application software packages, due to the complexity of the application software package [49]. Not having the in-house expertise will result in appointing an IT application software package supplier to assist with the implementation of the application software package. This will further result in the IT project team consisting of both end users and the supplier of the application software package.

If the organisation decides to follow the supplier route, the end user may purchase the product (application 
software package) offered by the supplier without properly evaluating the business requirements (business processes) of the organisation. The end user will usually take the word of the supplier that the product is a perfect fit for the organisation's information needs and business processes, only realising at a later stage that the end product functionality does not meet the needs initially identified or defined. This is supported by the view expressed by Umble et al. [45] that most application software suppliers may go so far as to make assumptions about an organisation's business processes. In some instances, application software suppliers may pursue their creativity without regard for the client's business requirements [1]. For example, the supplier may not properly communicate to the organisation that the customisation features of the purchased application software package cannot be extended in general terms, as they are specific to the particular application software package [39].

The organisation is buying more than just an application software package from the supplier. The organisation is actually purchasing the software supplier's interpretation for many of the organisation's business processes. The organisation often accepts the supplier's assumptions about the organisation without proper evaluation of the business processes. The organisation then changes its existing procedures and processes to conform to what the supplier is selling. The result is an end product without the functionality required by the organisation [45]. Turbit [44] and Ke and Wei [26] support this view by stating that a common mistake made by organisations is that they try to change business processes to suit the functionality of the application software package. Organisations should rather evaluate and change the business processes and patterns of workflow to improve efficiency and select and purchase a product that is generally compatible with the business requirements [39].

Another mistake made by organisations is to acquire an application software package from the supplier with the lowest bid. Low buy-in also limits the participation mix of business and IT, which contributes to improper alignment of business processes of the organisation with the functionality of the application software package [44].

From the above it is clear that the supplier may well contribute towards an organisation not properly identifying its business requirements (specifically business processes), because the supplier is simply selling its product and neglecting the actual needs of the organisation. Organisations should start the implementation process by identifying the business requirements of the organisation and only thereafter select the application software package that is most suitable to address the business requirements.

\section{RESEARCH METHODOLOGY}

In this study, a historical analysis of the literature was conducted, which was utilised to help define and explain the IT gap that exists between the business processes of an organisation and the functionality of the application software package implemented. Webster and Watson [47] are of the opinion that an effective review of prior, relevant literature 'creates a firm foundation for advancing knowledge'. They add: 'It facilitates theory development, closes areas where a plethora of research exists, and uncovers areas where research is needed' [47]. Okoli and Schabram argue that a review of prior literature 'creates a solid starting point for all other members of the academic community interested in a particular topic' [31]. Furthermore, Fink's (as cited in Okoli \& Schabram) [31] definition of a rigorous stand-alone literature review suggests following a systematic methodological approach, explicit in explaining the procedures by which it was conducted and comprehensive in its scope by including all relevant items.

The historical analysis conducted in this study followed a concept-centric approach, as suggested by Webster and Watson [47], and a four-stage approach, as suggested by Sylvester et al. [40]. However, each stage was carried out iteratively and incrementally. Initially the article selection criteria were deliberately made broad, and the selection and number of articles included in this study varied as the author moved through the process. The research design (four-stage approach) was informed by a study on representing a heterogeneous research literature by Sylvester et al. [40]. The timeline distribution of the final selection of articles is between 1975 and 2012.

\subsection{The searching stage}

The strategy for the searches was deliberately broad and inclusive. Search terms included 'alignment', 'application software packages', 'information technology gap', 'package failure', 'misalignment', 'business processes', 'reengineering of business processes', 'business models', 'influence of package provider', 'package functionality' and 'data attributes'. Interloan services, library books, online bibliographic databases and professional subscriptions (for example IEEE, Science Direct, Ebsco Host) were sources used to conduct the literature study. No screening of the articles for reputation of journal, quality of methods, academic focus or any other criteria took place. The only requirement was that the articles should fall broadly within the scope of the study. This process provided a set of 169 possible items.

This stage gave the author an idea of the diversity and scope of the topic. The scope was then adjusted to include seminal articles. The following was taken into consideration during the selection of seminal articles: Does it make a substantial scholarly contribution? Has the specific article been cited sufficiently and often enough to be regarded as a guiding influence? The specific articles chosen for this study were monitored for objectivity and appropriate distribution across the timeline.

\subsection{The mapping stage (article selection)}

This stage was the first step towards making sense of the 169 possible items identified. This stage entailed refining the original selection of items according to recurring themes. For the purpose of this study, the recurring themes included 'alignment/misalignment of information systems and/or application software packages', 'application package failures/successes', 'information technology gap', 'reengineering of business processes' and 'functionality of 
application software packages'. This process was followed by a more detailed reading of the abstracts, introductions and conclusions of the articles. The result of this stage was that the original selection of items was reduced to 87 items.

The outcomes of this stage helped the author to establish the conceptual, theoretical and methodological concerns with regard to the study.

\subsection{The appraisal stage}

A detailed reading of each article took place during the appraisal stage. The different themes were compiled into thematic context by making notes on the articles.

This stage concluded with the identification of the main concepts and aspects that should be considered and addressed with regard to the definition and explanation of the IT gap that exists between business processes and application software packages.

\subsection{The synthesis (data-analysis) stage}

In the data-analysis stage, the author followed activities such as combining, integrating, modifying, rearranging, composing and generalising concepts that were identified during the appraisal stage to ensure that the golden thread or theme of this study, namely aligning business processes with the end functionality of the application software package, runs throughout the article.

In the next section, the concept of the IT gap is defined and explained.

\section{DEFINING AND EXPLAINING THE IT GAP}

The IT gap, specifically in terms of application software packages, is attributed to a gap that exists between business processes and the functionality the application software package has to offer to translate the business processes of an organisation into digital form when implementing and configuring an application software package [27]. This is supported by Stapelberg [39], who states that there is a gap between the business requirements (or specific business processes) and the IT programmer's (supplier) interpretation of the requirements. Top management should address the IT gap by aligning business processes and the IT project strategy (the end functionality of the application software package) to achieve business performance gains [46]. Before top management can address the IT gap, they should properly understand what exactly the IT gap is. This study addresses the IT gap that exists between the business processes of the organisation and the functionality of the application software package.

The IT gap with regard to application software packages can be divided in the following components [27]:

- Business model

- Business processes

- Functionality of package

- Data attributes

The IT gap components are illustrated in Figure 1 and are explained further in the remainder of this section. For the purpose of explaining the IT gap components, the following terms are used with the following meanings: Supplier - the supplier refers to the provider (or vendor) of the application software package and represents the IT side, as indicated in Figure 1; Client - the client refers to the organisation acquiring the application software package and represents the business side, as indicated in Figure 1.

\section{IT gap component: Business model}

I1 - Supplier:

The business model is technical to the supplier and difficult to conceptualise [27]. A business model may be defined as the rationale of how an organisation creates, delivers and captures value [25]. Furthermore, the business model typically consists of the industry assumptions (theory of business), strategic objectives, business policies, business processes of an organisation and business imperatives (thrust of activities; things that are crucial and that need to be performed exceptionally well with regard to IT for a business to succeed in a specific industry, for example information requirements of application software package and an affordable and low-risk application software package) [27].

Usually top management (client) expect from IT (supplier of the application software package) to implement an application software package that supports the organisation's business model and specific business processes. The specific business model is framed within an industry context as well as the maturity scale of the organisation [27].

Furthermore, it is important that both the supplier and the client need to prepare a business case at the onset of the IT project. A business case captures the reasons for initiating a project [36]. To enable IT to prepare the business case, they need a proper understanding of the organisation's business model and specific business processes. However, many application software package implementations already fail at this stage of the implementation of the package. The reason for failure at the initiation stage is answered by Paul (as cited in Smith) [37], who states that it is quite obvious to articulate the business case at the start of the project. However, the supplier of the package usually does not perform a business case analysis prior to the start of the project, and if it does, the business case is usually not used once the project starts.

In many instances, the organisation's (client) business case differs dramatically from the supplier's business case in that the organisation's business case covers the benefits to the organisation in contrast to its costs and risks. As for the supplier, the business case in many instances may simply concern making a profit [30].

\section{I2 - Client:}

To top management, the business model is non-technical [27]. Establishing clear goals is difficult [3], because the supplier and client use different terminology to address the same aspects. Furthermore, these requirements are communicated to the supplier at a very high level [27]. For example, the client would use terms such as (in an accounting environment) order entry and invoicing, while the supplier would use tables and fields to define the exact same component in computer terms [27]. 


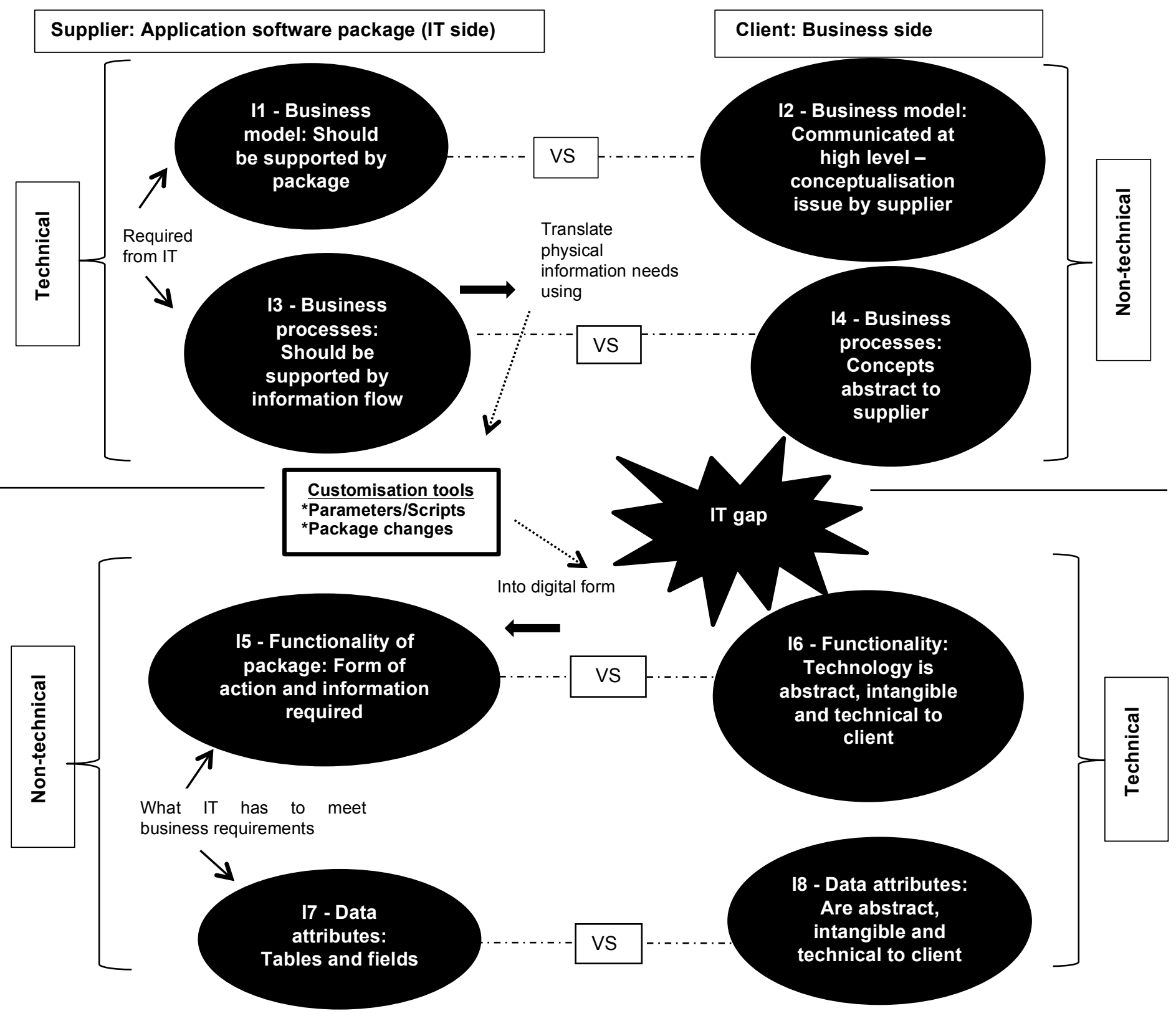

Figure 1: Illustration of the IT gap

\section{IT gap component: Business processes}

\section{I3 - Supplier:}

Business processes are technical to the supplier [27] and it is difficult for the supplier to conceptualise a business process [27]. Business processes are part of the business model but should be defined separately, as it is the business processes that need to be aligned with the application software package [27]. It is important that business processes should be supported by the information flow of the application software package [27]. This is supported by the view expressed by Winter [49], namely that application software packages used in areas such as data processing, strategies and process control need to have a flow to the sequence of operations that are required to be carried out by the application software package [49].

Information flow or workflow applications may be defined as applications that go sequentially through all the activities of a process [12]. However, it is important to remember that many application software packages have 
basic pre-defined workflow, basic parameters, basic reportwriting and limited customisation capabilities [27]. If the supplier neglects to properly evaluate current business processes at the start of the implementation process, it may lead to an unsuccessful application software package (without the necessary functionality) being implemented (Paul, as cited in Smith) [37].

\section{I4-Client:}

Business processes are non-technical to the client [27]. Top management should select the application software package that best suits the business requirements of the organisation [27]. However, in many instances, top management (client) first select an application software package and try to change the business processes to suit the application software package instead of changing business processes to improve efficiency [44]. If top management try to change business processes to suit the application software package, it may lead to the application software package not having the functionality (improper alignment) as required by the organisation [27].

\section{IT gap component: Functionality of package}

\section{I5 - Supplier:}

The functionality of the package is non-technical to the supplier [27]. Functionality can be defined as what is needed (business requirements) by the user of the package as well as requested properties of inputs and outputs of the application software package [41].

The supplier would translate physical information requirements (business processes) into digital form using customisation tools such as parameters/scripts and package changes if the functionality of the package does not perfectly fit the business processes of the organisation. However, the intended functionality might not always be the implemented functionality due to improper evaluation of business processes at the start of the implementation process [27].

Furthermore, application software package environments may be either functional-rich (application software needs to perform complex calculations, usually using simple data structures for calculation) or data-rich (application software needs to perform simple calculations using data structures that are more complex). In order for the supplier to determine whether the application environment is functional- or data-rich, the supplier should first understand whether an organisation's business processes are functional- or data-rich [27].

Another problem is suppliers often use generic supporting frameworks (for example PRojects IN Controlled Environments - PRINCE2) to assist them with the implementation and configuration of an application software package. It is important for the supplier to note that generic supporting frameworks do not give guidance on 'how' the functionality of the specific application software package works. It is advisable to also obtain a product-specific supporting framework to assist the supplier with the implementation [27]. However, the product-specific supporting framework (for example Microsoft Dynamics Sure Step) may also have limitations, which could result in not adequately addressing the alignment of the business processes with the functionality of the end product [27].

I6-Client:

The functionality of the application software package is highly technical to the client [27]. Furthermore, technology is abstract and intangible to the client and the client does not understand what actions need to be performed to translate physical business processes into digital requirements. The client only knows what the end product should be able to do [27].

\section{IT gap component: Data attributes}

I7 - Supplier:

To the supplier, data attributes are non-technical [27]. Data attributes refer to the technical components (or building blocks) of an application software package that are used to build and configure the specifications that the application software package should meet. Technical components may include table objects, code units, form objects, reports and data ports [22]. Apart from the guidance on implementing the application software package that is received once the package is acquired, little additional guidance is available when configuring technical components of the application software package [27].

\section{I8 - Client:}

Data attributes are very technical, abstract and intangible to the client [27]. Most members of management have little or no knowledge of configuring the technical components of the application software package.

\section{RECOMMENDATIONS FOR BUSINESS-IT STRATEGIC ALIGNMENT}

After taking into consideration the results of the literature review conducted by the author, recommendations are made on how to reduce the IT gap that exists between the client's business processes and the end functionality of the application software package. The recommendations will be made per IT gap component, as discussed in Section 5.

\section{IT gap component: Business model (I1 \& I2)}

- Distinguish between business objectives and business imperatives: Top management should distinguish between business objectives (essential things that need to be performed for a business to survive, for example to make a profit) and business imperatives (thrust of activities - things that are crucial and that need to be performed exceptionally well with regard to IT for a business to succeed in a specific industry, for example information requirements of application software package and an affordable and low-risk application software package).

- Obtain input from all stakeholders: Although the business imperatives (business processes) should be driven from top management, input from all other stakeholders (the board, IT and the end users of the application software package) must be acquired. The involvement of all parties is necessary to ensure that 
all stakeholders commit to the objectives of the project. End users may make valuable contributions because they are the persons who will work with the new application software package on a daily basis.

- Create a 'bridging' language: A 'bridging' language should be created by appointing a person with both an IT and a business background to facilitate communication between the supplier and the client. The 'bridging' language would also assist in the conceptualisation issue that the supplier may experience.

\section{IT gap component: Business processes (I3 \& I4)}

- Involve key people: It is crucial that key people who have an in-depth understanding of the specific information requirements and business processes (and why processes happen as they do) are involved in the evaluation of business processes.

- Document and evaluate current business processes: Top management should evaluate, define and document the current business processes with the vision of how they can improve the efficiency of the organisation's business processes. The business processes should be documented and defined clearly at the onset of the project in order for the supplier to understand how users would use the application software package. Furthermore, proper documentation will enable the supplier to perform its own business case analysis at the start of the implementation process. The documentation of both the client and the supplier should be reviewed prior to the start of the implementation and if necessary be explained to each other to ensure mutual understanding of the business requirements between both parties.

If top management are unsure of how to analyse current business processes, external consultants (other than the proposed supplier responsible for implementation of the application software package) may be employed temporarily to assist in the process. For example, an external auditor may be temporarily employed to assist top management in evaluating the current business processes.

- Obtain proposals from multiple suppliers: Before deciding on a supplier to implement the application software package, top management should consider obtaining proposals from more than one supplier selling different application software packages. Obtaining proposals from more than one supplier may assist top management in selecting the best way to deliver the end product through scenario comparison. Top management should consider not only cost but also the functionality and adaptability of the application software package.

- Evaluate reputation of suppliers: Top management should evaluate the reputation of the supplier before a final decision is made on which supplier should be appointed. Top management may request a list of successful implementations from the supplier, and these organisations may be contacted by the organisation in order to evaluate to what extent the other organisations were satisfied with the services received from the specific supplier. Top management may enquire whether the supplier was only selling its product or whether it actually assisted in improving the organisation's business processes.

- Evaluate and compare supplier proposals: Top management should contact the proposed suppliers and request proposals from the suppliers mapping to what extent their product (application software package) will fit the improved efficiency of the organisation's business processes.

If the organisation does not have an IT department, top management should consider temporarily employing an IT consultant (other than the supplier) to evaluate the mapping. The client, together with the assistance of the IT department or external consultant, may then measure the application software package in terms of where the organisation's business processes are now and where they want to be at the end of implementation.

- Evaluate level of application software package customisations required: It is the responsibility of the client to ask the supplier to what extent the application software package needs to be customised. If considerable customisation is required, the client should consider acquiring another package.

\section{IT gap component: Functionality of package (I5 \& I6)}

- Properly understand business processes by supplier: Only after the supplier has conducted and documented the business case analysis (including determining whether the business processes are functional- or data-rich) and properly understands how the users will use the application software package, can the supplier start translating the business processes into digital form.

- Test functionality at end of each stage: After the completion of each stage of the implementation of the application software package, the end users of the application software package should test the specific stage before proceeding to the next implementation stage. Testing each stage will identify any misunderstandings encountered at the onset of the implementation process during the analysis of the business case.

- Limit customisations: The supplier may only consider customisation when the functionality of the application software package fails to address critical business requirements. If the supplier only informs the client after the implementation of the application software package has started that considerable customisation is required, the client should evaluate whether it might be more beneficial to end the project and select another application software package rather than proceeding with the current implementation.

The supplier should limit package changes to a minimum, as customisations may create a retrofit issue when new updates need to be installed. Retrofit may be defined as reversing changes (or customisations) before the package can be upgraded [27]. However, if customisations are necessary, the supplier should document exactly what 
changes were made in order for the supplier responsible for future upgrades to know exactly what to retrofit.

\section{IT gap component: Data attributes (I7 \& I8)}

- Define technical components: The supplier should ensure that each technical component of the information requirements is properly defined. For example, in an accounting environment, orders and invoicing should each be defined in terms of tables and fields.

- Obtain adequate knowledge of technical components required: The supplier should ensure that the whole project team is accustomed to the technical components of the application software package that needs to be implemented. If all team members are not familiar with the technical components, the project manager should make arrangements for the necessary training of the team members prior to the start of the project.

- Mentor first-time team members: If it is the first time a specific team member of the supplier is responsible for building the requirements of the application software package, it is the responsibility of the supplier to ensure that the team member is assisted or mentored by another team member who has the necessary experience and skills in implementing the specific application software package.

\section{CONCLUSION}

The first step towards achieving strategic alignment between the business processes of the organisation and functionality of the application software package is to gain a proper understanding of business processes and to evaluate how the business processes may be improved to be more efficient. Only then should the organisation decide on an application software package that would best suit the organisation's business processes. The end result will be proper alignment with less implementation failures and more successful application software package implementations.

\section{REFERENCES}

[1] Agarwal, N. \& Rathod, U. 2006. Defining 'success' for software projects: An exploratory revelation. International Journal of Project Management, 24:358-370.

[2] Ahmad, A.A. \& Newman, M. 2009. The transfer of technology and knowledge: A story of an enterprise system implementation, in $17^{\text {th }}$ European Conference on Information Systems. Manchester: Manchester Business School: 1-13.

[3] Aken, A. 2008. CHUNK: An agile approach to the software development life cycle. Journal of Internet Commerce, 7(3):313-338.

[4] Al-Mashari, M., Al-Mudimigh, A. \& Zairi, M. 2003. Enterprise resource planning: A taxonomy of critical factors. European Journal of Operational Research, 146:352-364.
[5] Al Neimat, T. 2005. Why IT projects fail. The Project Perfect White Paper Collection [Online]. Available: http://sct.emu.edu.tr/courses/mtit/itec580/userfiles/file s/info it projects fail.pdf [15 August 2012].

[6] Brynjolfsson, E. \& Hitt, L.M. 1998. Information technology and organizational design: Evidence from micro data [Online]. Available: http://www2.dse.unibo.it/santarel/BrynjolfssonHitt199 8.pdf [15 August 2012].

[7] Brynjolfsson, E. \& Mendelson, H. 1993. Information systems and the organization of modern enterprise. Journal of Organizational Computing, 3(3): 245-255.

[8] Ceruzzi, P.E. 2000. A history of modern computing. Cambridge, MA.

[9] Chan, Y., Huff, S., Barclay, D. \& Copeland, D. 1997. Business strategic orientation, information systems strategic orientation and strategic alignment. Information Systems Research, 8(2):125-150.

[10] Chao, C. \& Chandra, A. 2012. Impact of owner's knowledge of information technology (IT) on strategic alignment and IT adoption in US small firms. Journal of Small Business and Enterprise Development, 19(1):114-131.

[11] Chen, C.C., Law, C.C.H. \& Yang, S.C. 2009. Managing ERP implementation failure: A project management prospective. IEEE Transactions on Engineering Management,56(1): 157-170.

[12] Collaborative computing. S.a. [Online]. Available: http://www.adaptivesoftware.biz/archive/documents/C ollaborative\%20Computing.doc [15 August 2012].

[13] Dalcher, D. 2009. Software project success: Moving beyond failure. Upgrade, X(5): 42-50.

[14] Doukidis, G.I., Lybereas, L. \& Galliers, R.D. 1996. Information systems planning in small business: A stages of growth analysis. Journal System Software, 33:189-201.

[15] D'Souza, D. \& Mukherjee, D. 2004. Overcoming the challenges of aligning IT with business. Information Strategy: The Executive's Journal, 20(2):23-31.

[16] Duhan, S. 2007. A capabilities based toolkit for strategic information systems planning in SMEs. International Journal of Information Management, 27:352-367.

[17] Ehie, I.C. \& Madsen, M. 2005. Identifying critical issues in enterprise resource planning (ERP) implementation. Computers in Industry, 56:545-557.

[18] Eveleens, J.L. \& Verhoef, C. 2010. The rise and fall of the chaos report figures [Online]. Available: http://www.cs.vu.nl/ X/chaos/chaos.pdf [15 August 2012].

[19] Hammer, M. 1990. Reengineering work: Don't automate, obliterate [Online]. Available: http://www.cosinconsulting.com.br/WebSite/artigos/re engineering work dont automate obliterate.pdf [18 June 2012].

[20] Henderson, J. \& Venkatraman, N. 1993. Strategic alignment: Leveraging information technology for 
transforming organisations. IBM Systems Journal, 32(1):4-16.

[21] Hirschheim, R. \& Sabherwal, R. 2001. Detours in the path toward strategic information systems alignment. California Management Review, 44(1):87-108

[22] Hvitved, T. 2009. Architectural analysis of Microsoft Dynamics NAV [Online]. Available:

http://3gerp.iwvi.unikoblenz.de/docs/hvitved09nav.pdf [21 June 2011].

[23] IT Cortex. 2005. Success assessment [Online]. Available: http://www.it-cortex.com/Failure.htm [31 May 2011].

[24] Johansson, H.J. 1993. Business process reengineering: Breakpoint strategies for market dominance. Wiley.

[25] Karl, M. 2011. Advances in software economics: A reader on business models and partner ecosystems in the software industry. Norderstedt: BOD.

[26] Ke, W. \& Wei, K.K. 2008. Organizational culture and leadership in ERP implementation. Decision Support Systems, 45:208-218.

[27] Kruger, W. 2011. Addressing application software package project failure: Bridging the information technology gap by aligning business processes and package functionality. Unpublished mini thesis. Stellenbosch: Stellenbosch University.

[28] Luftman, J. 2000. Assessing business-IT alignment maturity. Communications of the Association for Information Systems, 4(14):1-50.

[29] Nixon, P., Harrington, M. \& Parker, D. 2011. Leadership performance is significant to project success or failure: A critical analysis. International Journal of Productivity and Performance Management, 61(2):204-216.

[30] Office of Government Commerce. 2009. Managing successful projects with PRINCE2 [Online]. Available:

http://www.bestpracticebookstore.com/books/info PR INCE2Manual2009PDF.html [15 August 2012].

[31] Okoli, C. \& Schabram, K. 2010. A guide to conducting a systematic literature review of information systems research. Sprouts: Working Papers on Information Systems, 10(26):1-49.

[32] Peppard, J., Lambert, R. \& Edwards, C. 2000. Whose job is it anyway? Organizational information competencies for value creation. Information Systems Journal, 10:291-322.

[33] Poli, M. \& Shenhar, A.J. 2003. Project strategy: The key to project success. Management of Engineering and Technology, 20-24 July:231-235.

[34] Reich, B. \& Benbasat, I. 1996. Measuring the linkage between business and information technology objectives. MIS Quarterly, 20(1):55-78.

[35] Sauer, C. \& Cuthbertson, C. 2003. The state of IT project management in the UK 2002-2003 [Online]. Available:

http://www.bestpracticehelp.com/The State of IT Pr oject Management in the UK 2003 2004.pdf [31 May 2011].
[36] Schaltegger, S. \& Wagner, M. 2006. Managing the business case for sustainability: The integration of social, and economic performance. Sheffield: Greenleaf.

[37] Smith, J. 2002. Why information technology software projects fail in South Africa. Unpublished mini study project. Johannesburg: Technikon Witwatersrand.

[38] Soh, C. \& Sia, S.K. 2004. An institutional perspective on sources of ERP package-organisation misalignments. Journal of Strategic Information Systems, 13:375-397.

[39] Stapelberg, E.P. 1994. The implementation of customisable software packages for business practice. Unpublished doctoral dissertation. Pretoria: University of Pretoria.

[40] Sylvester, A., Tate, M. \& Johnstone, D. 2011. Beyond synthesis: Re-presenting heterogeneous research literature. Behaviour \& Information Technology. doi: 10.1080/0144929X.2011.624633.

[41] US Department of Defence. Systems engineering fundamentals. 2001.[Online]. Availailable: http://www.dau.mil/pubscats/PubsCats/SEFGuide $\% 20$ 01-01.pdf [15 August 2012].

[42] Taylor, A. 2000. IT projects: Sink or swim. The Computer Bulletin January 2000 [Online]. Available: http://itnow.oxfordjournals.org/content/42/1/24.full.pd f+html [30 May 2011].

[43] Tillmann, G. \& Weinberger, J. 2004. Baseline. Technology never fails, but projects can [Online]. Available: http://www.baselinemag.com/c/a/ProjectsManagement/Technology-Never-Fails-But-ProjectsCan/ [15 August 2012].

[44] Turbit, N. 2005. ERP implementation - the traps. The Project Perfect White Paper Collection. [Online]. Available: http://www.vvsgidas.lt/get.php?id=315 [15 August 2012].

[45] Umble, E.J., Haft, R.R. \& Umble, M.M. 2003. Enterprise resource planning: Implementation procedures and critical success factors. European Journal of Operational Research, 146:241-257.

[46] Velcu, O. 2010. Strategic alignment of ERP implementation stages: An empirical investigation. Information \& Management, 47:158-166.

[47] Webster, J. \& Watson, R.T. 2002. Analyzing the past to prepare for the future: Writing a literature review. MIS Quarterly, 26(2):xiii-xxiii.

[48] Weston, F.C. 2001. ERP implementation and project management. Production and Inventory Management Journal, 42(3/4):75-80.

[49] Winter, M. 2006. Investigation into project management failure within information technology systems projects. Unpublished mini study project. Stellenbosch: Graduate School of Business of the University of Stellenbosch.

[50] Zand, D.E. \& Sorensen, R.E. 1975. Theory of change and the effective use of management science. Administrative Science Quarterly, 20(4):532-545. 